\title{
External Input and Natural Resource Effects on Regional Comparative Advantage
}

\author{
Thomas A. KLAASEN\#
}

In recent years, there has been interest expressed in regional comparative advantage in the United States and empirical studies have been undertaken. (1) These tests found the variables normally associated with the Ricardian model (labor cost or labor productivity) and the Heckscher Ohlin model (capital-labor ratios and relative capital and labor endowment) to be poor predictors of regional (South-non-South) industry concentration in the U. S. A suggested explanation for these results is that the role of natural resources was ignored. In an effort to confirm this, a new variable was added in one set of tests. (2)

The variable, called the coefficient of resource dependency, is defined as the ratio of value added to value of shipments for each industry. It is then, the percent of the value of output that was added by the firm, from which the percent of value of output that was contributed through purchases from outside (other industry) sources can be computed. The variable can be written as $\frac{v_{i}}{\mathrm{o}_{i}}$, where $V_{i}$ is the dollar value-added for the ith industry, and $\mathrm{O}_{i}$ is the dollar value of output for the $i$ th industry. $V_{i}$ is, of course, equal to $\mathrm{O}_{i}-\mathrm{P}_{i}$, where $\mathrm{P}_{\mathrm{i}}$ is the dollar value of purchased inputs from all other industries, and equal to $\Sigma p_{j}^{i}$, the sum of purchases from the $\mathrm{j}$ industries for the ith industry.*

Rank correlation tests and regression analysis showed a highly significant relationship between regional industry concentration and the coefficient of resource dependency, and thus the pattern of industry concentration in the South was partially explained where the traditional trade models had failed. Because industries more heavily concentrated in the South indicated a greater reliance on external inputs, the implication is that natural resources have a significant impact in determining industry location in the South, although the variable's preciseness must be questioned as natural resources are not the only inputs purchased from other industries.

The purpose of this paper is to more accurately specify the significance of external inputs and to strengthen the argument that natural resources play an important role in regional industry concentration. Given that external inputs do influence industry location (concentration), one would expect that not only would the degree of dependency on outside resources industries be important, but also that the location of these supplying industries might have an influence. In fact,

*Let $\mathrm{j}$ refer to "input" or supplying industries, while $\mathrm{i}$ will denote "output" industries, i.e. those whose location (concentration) are to be explained, and where $i=1 \ldots 62$, while $j=1 \ldots n$. 
because there is no "a priori" reason for regional industry concentration to be determined by dependency alone, location may be a more important factor. Thus, if supplying industries were predominantly located in the South, one would expect the producing industries to be more heavily concentrated in the South. In an effort to validate this, a series of rank correlations tests (3) and regression analysis was undertaken.

To obtain data, Fortune Input-Output Tables for 1966 were consulted (4). This table, in part, shows the ratio of the value of manufactured inputs to the total value of output for a matrix of 62 manufacturing industries. The industry code used in the Fortune table was comparable to the SIC code allowing computation of regional industry concentration from the Census of Manufacturers.

(5) Specifically, industry concentration for the South was computed as $\frac{v_{i}^{s}}{v_{i}^{n}}$, where $V_{i}$ is as defined earlier, and the superscripts indicate the South and non-South regions.

Three other variables were also computed. The first was the degree to which the total value of output of each manufacturing industry, $\mathrm{O}_{\mathrm{i}}$, depends on inputs from all other manufacturing industries in the matrix. That is, purchased manufactured inputs account for some $X$ percent of total value of output for each industry, and is written as $\frac{\mathrm{P}_{j}^{\mathrm{i}}}{\mathrm{O}_{\mathrm{i}}}$. Of the 62 manufacturing industries, six had a value of purchased manufactured inputs of less than ten percent of total value of output and were dropped from the sample.

The second variable computed was a weighted average concentration ratio for all input industries that contributed at least one percent to the total value of output for each "output" industry. This can be written as $\mathrm{W}_{\mathrm{i}}=\sum_{j=1} \mathrm{w}_{j} \frac{\mathrm{v}_{\mathrm{j}}^{\mathrm{s}}}{\mathrm{v}_{\mathrm{j}}^{\mathrm{n}}}$, where $\mathrm{w}_{\mathrm{j}}=\frac{\mathrm{P}_{\mathrm{j}}^{\mathrm{i}}}{\mathrm{O}_{\mathrm{i}}}$.

The third variable computed was the percentage contribution of total manufactured inputs weighted by the average concentration of the inputs, written as $\mathrm{Z}_{\mathrm{i}}=\frac{\mathrm{P}_{\mathrm{i}}}{\mathrm{O}_{\mathrm{i}}} \mathrm{W}_{\mathrm{i}}$.

Before empirical testing can begin, testable hypotheses must be formulated. Because of the results of previous works cited, one hypothesis is that industry concentration in the South is related to the degree to which the total value of output of an industry depends on inputs from other manufacturing industries. Specifically, this dependency, $\frac{\left(\mathrm{P}_{\mathrm{i}}\right)}{\left(\mathrm{O}_{\mathrm{i}}\right)}$, was hypothesized to have a positive influence on industry concentration in the South. (While the dependency measure used in these tests is similar to the coefficient of resource dependency mentioned earlier, a critical difference, to be considered later, does exist.) 


\section{CORRECTION}

Volume 4 , Number 1 (Spring 1974)

Two additional hypotheses state that industry concentration is a function of the location of manufactured inputs as expressed in $W_{j}$ and $Z_{i}$. Because all concentration variables were ranked in ascending order according to their degree of concentration in the South, positive relations were hypothesized. The results of the rank correlation tests are shown in Table 1.

In an effort to find the relative coniribution to the explanation of Southern industrial concentration by input percentage and input concentration, a multiple regression was run. Relative industry concentration in the South,

$\frac{v_{i}^{s}}{v_{i}^{n}}$, was the dependent variable, while input percentage $\frac{P_{i}}{0_{i}}$ and average

concentration of input $\left(W_{i}\right)$ were used as independent variables. The regression coefficients confirm the results of the rank correlation tests: input

concentration (location) is important, while input percentage contribution is not. (See Table 2.) The multiple correlation coefficient was found to be .517 , whose $F$ statistic was 9.693 , significanc at the .001 level. 
Two additional hypotheses state that industry concentration is a function of the location of manufactured inputs as expressed in $\mathrm{W}$ and $\mathrm{Z}$. Because all concentration variables were ranked in ascending order according to their degree of concentration in the South, positive relations were hypothesized. The results of the rank correlation tests are shown in Table 1.

In an effort to find the relative contribution to the explanation of Southern industrial concentration by input percentage and input concentration, a multiple

regression was run. Relative industry concentration in the South, - , was the de-

pendent variable, while input percentage - and average concentration of input (W ) were used as independent variables. The regression coefficients confirm the results of the rank correlation tests: input concentration (location) is important, while input percentage contribution is not. (See Table 2.) The multiple correlation coefficient was found to be .517 , whose $\mathrm{F}$ statistic was 9.693 , significant at the .001 level.

\section{TABLE 1}

Rank Correlation Test Results

\begin{tabular}{ccccc}
\hline $\begin{array}{c}\text { Dependent } \\
\text { Variable }\end{array}$ & $\begin{array}{c}\text { Independent } \\
\text { Variable }\end{array}$ & $\begin{array}{c}\text { Hypothesized } \\
\text { Sign }\end{array}$ & Coefficient & $\begin{array}{c}\text { Level of } \\
\text { Significance }\end{array}$ \\
\hline$\frac{\mathrm{v}_{\mathrm{i}}^{\mathrm{s}}}{\mathrm{v}_{\mathrm{i}}^{\mathrm{n}}}$ & $\frac{\mathrm{P}_{\mathrm{i}}}{\mathrm{O}_{\mathrm{i}}}$ & + & -.003 & n.s. \\
\hline$\frac{\mathrm{v}_{\mathrm{i}}^{\mathrm{s}}}{\mathrm{v}_{\mathrm{i}}^{\mathrm{n}}}$ & $\mathrm{W}_{\mathrm{i}}$ & + & .336 & .05 \\
\hline$\frac{\mathrm{v}_{\mathbf{i}}^{\mathbf{s}}}{\mathrm{v}_{\mathbf{i}}^{\mathbf{n}}}$ & $\mathrm{Z}_{\mathrm{i}}$ & + & .244 & .05 \\
\hline
\end{tabular}

TABLE 2

Results of Multiple Regression Analysis*

\begin{tabular}{cccc}
\hline $\begin{array}{c}\text { Measure of } \\
\text { Concentration }\end{array}$ & $\mathrm{b}_{0}$ & $\mathrm{~b}_{1}$ (Standard Error) & $\mathrm{b}_{2}$ (Standard Error) \\
\hline$\frac{\mathrm{v}_{\mathbf{i}}^{\mathbf{s}}}{\mathrm{v}_{\mathbf{i}}^{\mathbf{n}}}$ & 0.08644 & $-0.00052(0.0014)$ & $0.5052(0.1159)$
\end{tabular}

$*$ The regression equation is written as: $\mathrm{Y}=\mathrm{b}_{0}+\mathrm{b}_{1} \mathrm{x}_{1}+\mathrm{b}_{2} \mathrm{x}_{2}$, where $\mathrm{Y}=\mathrm{a}$ measure of industry concentration, $x_{1}=$ the percentage of inputs - , and $x_{2}=$ the concentration of inputs $\left(W_{1}\right)$. 
The fact that input percentage showed little relation to industry concentration in the South would at first appear to be contradictory to the results first mentioned in this paper: the importance of the coefficient of resource dependency. That is, the earlier used coefficient of resource dependency did indicate a strong relationship between industry concentration in the South and the degree to which each industry relies on purchasing inputs from outside resources.

The difference between these two sets of tests is that the measure of input purchases used in this paper includes only manufactured inputs, while the earlier measure included all purchased inputs, including natural resources and services such as warehousing, transportation, and advertising. Due to general availability of the latter three items, they are not apt to have an influence in industry concentration. By elimination then, natural resource inputs must be a significant factor in determining regional industry concentration.

The purpose of this paper was to offer more concrete evidence as to why the traditional trade models have failed to explain South-non-South relative industry concentration in the United States. Two conclusions can be stated. First, the degree of dependency on outside manufacturing of inputs in and of itself is not relevant, but the location of these inputs is. Second, the need for natural resource inputs will have a bearing on industry location.

\section{REFERENCES}

1. Moroney, J. R., and J. M. Walker. "A Regional Test of the Heckscher-Ohlin Hypothesis," Journal of Political Economy, 74 (1966), 573-586.

Klaasen, T. A. "Regional Comparative Advantage in the United States," Journal of Regional Sciences, 13 (1973), 97-105.

2. Klaasen, p. 100.

3. Kendall; M. G. Rank Correlation Methods. New York: Hofner Publishing, 1955.

4. Fortune's 1966 Input/Output Coefficients, Time, Inc. 1966.

5. U. S. Bureau of the Census. U. S. Census of Manufactures, 1962. Washington, D. C.: U. S. Government Printing Office, 1964. 